Letrônica, Porto Alegre, v. 7, n. 1, p. 155-178, jan./jun., 2014

\title{
UM ESTUDO SOBRE A COMPREENSÃO LEITORA DE ALUNOS DE 2 E 3 ANOS DO ENSINO FUNDAMENTAL
}

\author{
A STUDY ABOUT READING COMPREHENSION OF 2 ${ }^{\text {ND }}$ AND $3^{\text {RD }}$ GRADE \\ STUDENTS OF ELEMENTARY SCHOOL
}

\author{
Letícia da Silva Barboza* \\ Vera Wannmacher Pereira**
}

\begin{abstract}
Resumo: Este trabalho tem por objetivo apresentar os dados obtidos em uma pesquisa que visou averiguar o desempenho de crianças nas tarefas de compreensão de histórias. Os sujeitos foram alunos de $2^{\circ}$ e $3^{\circ}$ anos do Ensino Fundamental de uma escola pública municipal, na região metropolitana de Porto Alegre. Como instrumento específico de pesquisa, foi utilizado um questionário com 8 perguntas relacionadas à história lida pelos sujeitos. Essa verificação foi realizada em dois momentos distintos mediante a leitura de narrativas diferentes. Neste estudo, foi considerada como variável a evidência de um ambiente de letramento no contexto familiar. Essa variável foi examinada mediante entrevista individual com os participantes. Ainda, foi analisada a escolaridade dos sujeitos de pesquisa. Os resultados atingidos por ambos os grupos revelaram que as crianças demonstraram um bom nível de compreensão nas tarefas propostas. Através de uma classificação para as respostas dadas pelos alunos, notou-se que o desempenho deles variou de alto para médio.
\end{abstract}

Palavras-chave: Compreensão leitora; Alunos do $2^{\circ}$ e $3^{\circ}$ anos do Ensino Fundamental; Ambiente de Letramento; Escolaridade.

\begin{abstract}
This paper aims to present the results from a study that investigated the performance of children in reading comprehension tasks. The participants were enrolled in the 2nd and 3rd grades of a public elementary school in the metropolitan area of Porto Alegre. We applied a questionnaire that included eight questions about a story read by the participants. The evaluation was applied at two different moments during the reading of two different stories. In addition to the questionnaire, we evaluated evidence of a household environment that stimulated literacy, by means of interviews with the participants, and the level of schooling of the participants. The results show that participants had an adequate level of comprehension for the tasks. The answers given by participants indicate that their performance ranged from high to medium.

Keywords: Reading comprehension; Students of 2nd and 3rd grade of Elementary School, Environment literacy; Schooling.
\end{abstract}

\footnotetext{
* Mestre em Letras pela Pontifícia Universidade Católica do Rio grande do Sul - PUCRS. E-mail: leticiabarboza1@hotmail.com.

** Doutora em Letras e professora do Programa de Pós-Graduação em Letras da PUCRS. E-mail vpereira@pucrs.br.
} 


\section{Introdução}

O domínio da habilidade de leitura é indispensável para que o sujeito esteja inserido em nossa sociedade letrada. Saber ler proporciona acesso à informação e ao conhecimento, contribuindo para a formação do ser humano. Essa habilidade tão importante caracteriza-se por ser complexa, uma vez que envolve diversos mecanismos, como a percepção, a cognição e a linguagem. Seu objetivo principal é a compreensão.

Neste trabalho, analisam-se os aspectos que abarcam a leitura, bem como a compreensão leitora sob o enfoque da Psicolinguística. Para tanto, são apresentados os estudos de importantes autores nessa área, como Smith (2003), Kleiman (1989), Kato (2007) e Scliar-Cabral (2003). Recentemente, os estudos das Neurociências têm contribuído significativamente para a compreensão do processamento da leitura. Devido a isso, as pesquisas de Dehaene (2012) também são mencionadas.

Os sujeitos participantes dessa pesquisa ${ }^{1}$ são 30 crianças, alunos do $2^{\circ}$ e $3^{\circ}$ anos do Ensino Fundamental de uma escola da rede pública municipal, na região metropolitana de Porto Alegre. Essas crianças, que possuem 7 e 8 anos de idade, ainda estão em processo de alfabetização. Atualmente, o período de alfabetização em nosso país contempla os três primeiros anos do Ensino Fundamental.

Para fins de pesquisa, foram escolhidos como participantes do presente estudo esses alunos, visto que se quer avaliar o desempenho desses sujeitos em tarefas de compreensão leitora, o que seria mais difícil com alunos do $1^{\underline{0}}$ ano do bloco de alfabetização. Isso porque, nesse ano escolar, o ensino é voltado ao processo de decodificação.

Como instrumento de verificação, foi aplicado, a partir da leitura da história, um questionário de compreensão de partes e fatos da narrativa. Com um intervalo de uma semana, os alunos realizam a mesma tarefa baseada em outra narrativa. Procura-se analisar também se o ambiente de letramento é uma variável a ser considerada nesse processo, que é averiguado através de um protocolo verbal de entrevista, além da escolaridade dos sujeitos.

\footnotetext{
${ }^{1}$ A pesquisa apresentada neste artigo é um recorte da dissertação de mestrado intitulada "A relação entre a compreensão leitora e a consciência textual: um estudo com alunos de $2^{\circ}$ e $3^{\circ}$ anos do Ensino Fundamental" realizada pela autora e orientada pela coautora deste trabalho.
} 
Este trabalho está dividido em duas partes. A primeira consiste nos referenciais teóricos que embasam a pesquisa. Na seção subsequente, parte-se para a exposição da metodologia utilizada, descrevendo-se os instrumentos para coleta de dados e a forma de análise. Finaliza-se com a exposição e os resultados encontrados, bem como as conclusões obtidas.

É importante ressaltar que existem poucos estudos que remetem à compreensão textual na fase de alfabetização. Dessa forma, este trabalho visa a contribuir para conhecimentos nessa área através da exposição e da análise dos dados obtidos nas tarefas de compreensão leitora executadas pelos sujeitos de pesquisa.

\section{Pressupostos teóricos}

É através da leitura que os indivíduos adquirem informações e conhecimentos, o que lhes permite o desenvolvimento de suas potencialidades e da própria dignidade humana. Devido a isso, os avanços tecnológicos e científicos, as mudanças na vida em sociedade não descartam a sua importância e a sua necessidade.

Assim, pode-se afirmar que o objetivo da habilidade de ler é a condução do sujeito à compreensão, que ocorre quando se descobre o sentido de um texto, ampliando experiências e saberes. É um processo que relaciona o novo com o velho, ou seja, através da leitura, o indivíduo modifica e complementa o seu conhecimento.

A fim de discutir esse processo de compreensão em crianças (alunos de $2^{\circ}$ e $3^{\text {o }}$ anos do Ensino Fundamental) o referencial teórico do presente trabalho está dividido em três tópicos. Ressalta-se a compreensão leitora, os fatores que a influenciam e o percurso realizado pelo leitor para chegar ao objetivo da habilidade de leitura, que é a compreensão.

\subsection{Compreensão leitora: ampliação de saberes e experiências}

\subsubsection{0 objetivo da leitura: compreensão leitora}

Segundo Smith (2003), a compreensão ou o entendimento é a base do aprendizado da leitura propriamente. A compreensão e o aprendizado são um processo 
que relaciona o novo ao velho. Para o autor, o significado não está no texto, uma vez que esse apenas fornece pistas ao leitor para chegar à compreensão. Essas pistas ativam o que o leitor tem em sua memória, relacionando o conhecimento novo, informações do mundo a sua volta, ao que já conhece, suas expectativas e suas intenções.

Já para Brandão e Spinillo (2001), a compreensão de textos é uma atividade de solução de problemas. A autora compara essa atividade à tradução, uma vez que a compreensão implica traduzir palavras em conhecimento, traduzir palavras em informação, ideias ou significado. É uma tarefa de natureza linguística, pois, para chegarse à compreensão de um texto, diversos elementos devem estar integrados, como o reconhecimento das letras, das palavras, o seu significado. É também uma tarefa de natureza cognitiva, uma vez que engloba aspectos como a memória, a percepção, a inteligência e outros. Assim, a leitura abrange mais do que a identificação das palavras: uma condição necessária, mas não suficiente.

Para Marcuschi (2004, p. 89), “compreender um texto não é uma ação apenas linguística ou cognitiva; é muito mais, é uma forma de inserção no mundo e um modo de agir sobre o mundo na relação com o outro dentro de uma cultura e uma sociedade". A compreensão é um processo inferencial, ou seja, uma atividade de construção do sentido do texto em que se parte de informações textuais (que o autor apresenta) e informações que os leitores colocam, originárias do seu conhecimento, ou da situação em que o texto foi produzido, para que haja a produção de sentido.

Nessa perspectiva, pode-se dizer que a compreensão é um processo de formar, elaborar e transformar o conhecimento anterior com uma nova informação. É um processo de complexidade crescente que se modifica a partir das interações com o meio, relacionando o que já se conhece com aquilo que se quer descobrir e experimentar, de acordo com o amadurecimento cognitivo.

A compreensão leitora não pode ser ensinada explicitamente, uma vez que ocorre a partir das práticas envolvendo a leitura. É uma busca pelo sentido. A maneira como se compreende algo em um momento específico pode ser inadequada mais tarde, porque utilizamos a nossa competência lexical, o nosso conhecimento sintático juntamente com o semântico, conhecimento de mundo e experiências pessoais, que são adquiridos e transformados ao longo de nossas vidas. 
Esse processo já começa nos primeiros anos de vida, antes de a criança aprender a ler, através de suas experiências no contexto familiar. Inicialmente, é mediado por um adulto ou outra criança mais velha que faz o papel de leitor para que a criança interprete e amplie seus conhecimentos linguísticos e seu conhecimento de mundo. Para ScliarCabral (2003), o estímulo do ambiente é fundamental para que a criança desenvolva as práticas de leitura e atinja o objetivo principal do ato de ler: compreender e interpretar um texto a fim de refletir sobre o mesmo, obtendo informações.

Diversos são os fatores que devem ser considerados para que o indivíduo consiga compreender um texto conforme já mencionado acima. Na próxima seção, são apresentados detalhadamente quais fatores estão envolvidos na compreensão leitora.

\subsubsection{Fatores que incidem sobre a compreensão leitora}

Kleiman (1989) salienta que a construção do sentido envolve a interação de três tipos de conhecimentos prévios do leitor: de mundo, linguístico e textual, que são adquiridos pelo leitor em suas experiências cotidianas. Dessa forma, o significado não está no texto, uma vez que esse apenas fornece as pistas para que o leitor chegue à compreensão. Essas pistas ativam o que o leitor tem na sua memória e ligam o conhecimento novo ao velho.

Colomer e Camps (2002) mencionam a integração entre esses elementos e destacam também que a compreensão de um texto está relacionada à intenção do leitor. A esse respeito, as autoras relatam que o leitor lê por várias razões, que vão desde o desejo de distrair-se até a busca pelo conhecimento. A forma como o leitor aborda o conteúdo a ser lido é determinante para a sua compreensão. Nesse sentido, a leitura realizada pelo leitor é de acordo com a sua finalidade, seu grau de exigência de compreensão sobre o assunto exposto no texto. Por exemplo, o leitor fará uma leitura mais minuciosa, mais detalhada para apreender o conteúdo de uma prova do que para ler uma notícia de jornal.

Smith (2003) também afirma que as pessoas leem por um determinado motivo que pode ser para encontrar um nome em uma lista ou deleitar-se com um romance. Se o indivíduo não possuir uma razão para ler, a leitura torna-se improdutiva. Leffa (1996, p. 13) salienta que "ninguém lê sem um objetivo, nem mesmo na escola". 
Quanto ao conhecimento prévio do leitor, Colomer e Camps (2002) o dividem em dois grupos: conhecimentos sobre o escrito e conhecimentos sobre o mundo. Quanto ao primeiro, destaca-se a adaptação do conteúdo do texto à situação comunicativa, ou seja, o leitor terá de entender o objetivo do autor, onde e quando se produz a linguagem utilizada na obra, além de contrastar com a sua finalidade de leitura.

Referente ao conhecimento sobre o escrito, destacam-se os conhecimentos paralinguísticos, isto é, convenções na organização da informação em um tipo específico de texto, como sumário e introdução, convenções na distribuição e separação do texto, o uso de parágrafos, capítulos, separação entre as palavras, e outros. Esses mecanismos têm a função de facilitar a leitura. Caso essa organização não ocorra, a tarefa do leitor torna-se mais complexa, uma vez que precisa, assim, deter-se nesses detalhes.

Um leitor competente realiza a leitura de um texto de forma automatizada; lê palavras habituais como se fosse um todo e de forma rápida, possuindo um conhecimento das relações grafofônicas. Entretanto, o leitor necessita, primeiramente, realizar a correspondência fonema-grafema em cada palavra, ou seja, terá que descobrir os princípios que regem o nosso sistema de escrita para, à medida que avance na habilidade de decodificar, fixar-se na compreensão.

A esse respeito, Dehaene (2012) explica que o sujeito, para se tornar um leitor competente, deve passar por etapas. A primeira etapa da leitura é chamada de logográfica ou pictórica. Nessa fase, a criança não compreende como a escrita organizase, pois se detém na forma, na cor, orientação das letras e curvas.

A segunda etapa é a fonológica e consiste na conversão dos grafemas em fonemas. Esse procedimento de decodificação se estabelece, tipicamente, entre os 6 e 7 anos de idade, nos primeiros meses de escola. A palavra deixa de ser tratada em sua globalidade. A criança aprende a prestar atenção aos pequenos constituintes das palavras. Adquire as correspondências que associam cada um desses elementos aos fonemas de sua língua e os reúne para formar palavras.

A terceira etapa é a ortográfica, cuja característica principal é o desaparecimento progressivo de toda a influência do tamanho da palavra. Na etapa precedente, a criança decifra as palavras penosamente, letra após letra, uma decodificação que se detecta facilmente: o tempo de resposta aumenta consideravelmente de acordo com o número de letras. À medida que a leitura se automatiza, o efeito do tamanho da palavra 
desaparece. Ele se torna totalmente ausente no bom leitor. Em resumo, essa etapa se caracteriza por um paralelismo crescente do reconhecimento das palavras.

Todavia, apenas a automatização da leitura não a torna eficaz. É preciso estabelecer uma relação entre a palavra e seu significado, bem como a posição da palavra e sua relação com as demais dentro do escrito. Dessa forma, o leitor precisa possuir determinados conhecimentos basilares sobre o uso da língua e a sua forma de organização. São necessários, assim, o conhecimento morfológico, o conhecimento semântico e o conhecimento sintático da língua, empregando-os e adaptando-os em diversos contextos de uso. Kato (2007) destaca que a compreensão não se dá de forma isolada, mas sim através das relações de um item com outros já aprendidos.

Sabendo que a compreensão dos elementos linguísticos não ocorre de forma isolada, o conhecimento sobre o texto é um requisito importante a ser considerado. Para compreendê-lo, é preciso que ele esteja bem estruturado, que frases e parágrafos estejam organizados, conferindo-lhe coesão e coerência. Além disso, conhecer diferentes gêneros textuais facilita a compreensão do texto, pois cada um deles apresenta uma estrutura característica que pode implicar diferentes procedimentos cognitivos para o processamento da leitura.

São muitos os conhecimentos que o leitor deve possuir sobre o escrito, a fim de entender um texto. Entretanto, saber as palavras e expressões de um texto, sua estrutura, o gênero em que esse se apresenta não são suficientes para uma compreensão global. É importante, também, relacionar o conhecimento linguístico ao conhecimento de mundo, integrando experiências pessoais ao conteúdo do texto, conforme já exposto. A esse respeito, Leffa (1996) menciona que, para compreender um texto, é necessário que haja uma relação recíproca entre texto e leitor, uma vez que apenas o encontro entre esses não remete ao significado, bem como a ênfase ou em um ou em outro.

Smith (2003) também considera que apenas a informação visual não é suficiente para a compreensão. Para o autor, o leitor deve fazer uso também da informação não visual, que é o conhecimento já armazenado na memória para complementar o sentido de um texto. Assim, quanto mais conhecimento não visual possuir o leitor, melhor será o seu entendimento. Diante do ato de ler, o leitor necessita comparar as informações obtidas no texto com aquelas que já possui. A partir do escrito, um leitor competente é capaz de identificar ideias implícitas, estabelecendo relações com seu conhecimento de 
mundo, fazendo uso dos elementos linguísticos e confrontando-os com esquemas já existentes em sua memória para chegar à significação.

Em virtude disso, Smith (2003) menciona que crianças em processo de aprendizagem da leitura e da escrita prendem-se muito à informação visual, apresentando dificuldades de compreensão. Ainda, informações que são tão óbvias para o leitor experiente, muitas vezes, não são para o sujeito aprendiz, impossibilitando, amiúde, a obtenção do sentido da sua leitura por não ter conhecimento ou a experiência sobre determinado assunto.

De acordo com o exposto, afirma-se que a integração entre os fatores que incidem sobre a compreensão do leitor é extremamente importante. Pode-se, a fim de melhor explicar a necessidade dessa interação, compará-los às peças de uma máquina, cujo andamento em conjunto permite o bom funcionamento da mesma, conforme Colomer e Camps (2002). Na próxima seção, é abordado como ocorre o processamento da leitura, como o leitor atinge o seu objetivo máximo ao ler, que é compreender.

\subsubsection{Caminhos percorridos pelo leitor para chegar à compreensão}

A habilidade de ler implica o processamento da informação que pode acontecer de forma ascendente, também denominado bottom-up, de forma descendente, conhecido também como top-down ou de forma interativa (KATO, 2007).

0 processamento bottom-up caracteriza-se por ser um processo de análise e de síntese do material escrito, em que o leitor constrói o sentido do texto a partir das pistas linguísticas encontradas no próprio texto. Assim, a leitura consiste no processo de decodificação dos grafemas em fonemas para a obtenção do significado. Nesse modelo de processamento, o leitor faz uso linear das palavras do texto para extrair o significado, não reconhecendo a relevância do contexto.

Todos os leitores passam pelo processo de decodificação dos sons da língua, sendo esse processamento mais evidente em crianças em fase de alfabetização. Leitores iniciantes realizam a leitura dessa forma: uma leitura minuciosa, lenta, considerando cada letra para formar o todo, prendendo-se apenas ao texto e demandando um grande esforço cognitivo para realizar essa tarefa. 
Entretanto, primeiramente, uma criança necessita reconhecer as letras que formam o nosso alfabeto, as suas diversas formas, os diversos tamanhos e sua posição. Além disso, um leitor aprendiz necessita de informações claras e precisas sobre a forma de organização do sistema de escrita, para que, aos poucos, familiarize-se com o mesmo, não ficando confuso diante de palavras que não conhece e letras não legíveis ou manuscritas.

À medida que as práticas de leitura passam a ser frequentes, esse processo automatiza-se e torna-se eficiente. 0 leitor proficiente realiza essa atividade rapidamente, sem perceber. Segundo Dehaene,

Leitores proficientes e hiper-treinados, nós temos a impressão de um reconhecimento global das palavras. É uma intuição enganosa. Nosso cérebro não passa diretamente da imagem das palavras ao significado. Inconscientemente, toda uma série de operações cerebrais e mentais se encadeia antes de uma palavra ser decodificada. Ela é dissecada, depois recomposta em letras, bigramas, sílabas e fonemas... (DEHAENE, 2012, p. 236).

0 autor, através de seus estudos, explica que o processamento bottom-up inicia na retina que capta os símbolos visuais, as letras, e as envia para a região occípitotemporal ventral esquerda. Tal processamento ocorre devido à reciclagem neuronal, ou seja, os neurônios dessa área cerebral especializam-se para o reconhecimento da palavra escrita. Assim, como o cérebro não foi desenvolvido para a leitura, aprender a ler parece ser uma grande mudança no cérebro de nossas crianças, senão a mais importante.

Ainda, tais estudos podem contribuir para o ensino da leitura. O professor, ao tomar conhecimento das etapas mencionadas acima, considerando a complexidade desse processo, pode ajudar seus alunos ao longo do percurso de forma mais eficaz, partindo de um ensino gradativo, apresentando as regularidades, o que é mais frequente na língua.

Ao contrário do modelo ascendente, no processamento descendente, o leitor constrói o sentido de um texto a partir de seu conhecimento de mundo. Nesse modelo, o leitor faz uso de seus conhecimentos prévios, armazenados na memória e ativados, a partir das pistas linguísticas deixadas pelo autor no material escrito. Segundo Kleiman e Moraes (2002, p. 62), “o significado de um texto não se limita ao que apenas está nele”. 
Portanto cabe ao leitor o esforço cognitivo para buscar informações extratextuais e chegar à significação.

Nenhum dos dois modelos apresentados consegue explicar de forma abrangente o complexo processo de compreensão de um texto. Devido a isso, a teoria interacionista propôs a integração do processamento ascendente (bottom-up) com o processamento descendente (top-down), passando os dois a ocorrerem de forma simultânea e complementar (KLEIMAN, 1989).

Para construir o sentido de um texto, o leitor usa as informações visuais do texto juntamente com seu conhecimento de mundo, pois a informação ocorre de ambos os modos: ascendente e descendente. Esses processos podem acontecer de forma alternada ou ao mesmo tempo, dependendo das características do texto, da capacidade de previsão do leitor, seu conhecimento prévio, sua memória e atenção, bem como da utilização de estratégias de leitura. Segundo Pereira e Scliar-Cabral (2012), o sucesso do leitor está na escolha do processo mais eficaz diante de cada situação de leitura, visto que diversos fatores influenciam na sua decisão e agem de forma interligada.

Reconhecendo-se os caminhos percorridos pelo leitor para obter a compreensão, na próxima seção, apresentam-se o instrumento de compreensão leitora e o procedimento de análise dos dados.

\section{Instrumento de avaliação da compreensão leitora e procedimento de análise}

Primeiramente, é importante ressaltar que os instrumentos de compreensão leitora, o procedimento de análise dos dados, bem como as demais etapas da pesquisa foram submetidos à apreciação do Comitê de Ética em Pesquisa da PUCRS. 0 parecer de aprovação é correspondente ao número: 435.840.

Para verificar a compreensão de fatos da história, os sujeitos participantes deviam responder às questões propostas referentes ao texto. Eram oito perguntas para cada história. Durante a primeira entrevista, os sujeitos liam a história "A flor e o passarinho" (Anexo 1), que foi utilizada por Brandão e Spinillo (1998), Fontes e Cardoso-Martins (2004) e Wolff (2008). Nesses estudos, a história foi apresentada em áudio ou lida pelo pesquisador. 
Inicialmente, a avaliadora solicitava que o aluno realizasse a leitura silenciosa seguida da leitura oral. Após a leitura, eram feitas as oito perguntas orais, em ordem fixa, algumas de natureza inferencial, sobre pontos específicos da história, verificando-se o grau de precisão na compreensão da mesma (Anexo 2). Vale ressaltar que as perguntas 1, 2 e 3 referiam-se à situação-problema; as perguntas 4, 5 e 6, à resolução do problema e as perguntas 7 e 8 ao desfecho/conclusão da história.

A segunda história chamava-se: "A abelha”, uma adaptação da Série Evolução da Vida, da editora Edelbra, sem data de edição, cujo autor é Cântara (Anexo 3). Essa história foi adaptada com a finalidade de resumi-la, retirar a parte final que fugia da sequência narrativa. As perguntas 1, 2, 3 e 4 referiam-se à situação-problema, às questões 5 e 6 à solução para o problema e as perguntas 7 e 8 ao desfecho da história (Anexo 4).

É importante mencionar que as histórias "A flor e o passarinho" e "A abelha" foram escolhidas por apresentarem uma estrutura já conhecida pelos sujeitos. Conforme já enfatizado neste trabalho, as narrativas apresentam um esquema que é considerado um facilitador para a memória. Ainda, o vocabulário de ambas as histórias é bastante simples, adequado para crianças em fase de alfabetização, bem como o tema selecionado, que é de interesse dos sujeitos, uma vez que envolve a natureza.

\subsection{Procedimento de análise de dados}

Para realizar a análise das informações coletadas, as respostas dos alunos foram quantificadas para que se pudessem interpretar os resultados. As respostas das crianças foram classificadas em três tipos conforme modelo proposto por Brandão e Spinillo (1998) e reaplicado por Wolff (2008):

a) TIPO 1 - Incongruentes: respostas do tipo "não sei" ou que não apresentam relação com a história ouvida;

b) TIPO 2 - Gerais: respostas que embora mantenham relação com a história são um tanto genéricas e imprecisas;

c) TIPO 3 - Respostas específicas e precisas.

Foi atribuído um valor para cada resposta para fins de análise. Para as respostas do tipo 1 foi atribuído o valor 0 (zero), para as de tipo 2, 10 pontos e as de tipo 3, 20 
pontos. Para essa classificação, a avaliadora contou com o auxílio de dois juízes, professores dos anos iniciais, todos já pós-graduados. Um cálculo das opiniões dos juízes, mais a da pesquisadora, foi feito, prevalecendo a da maioria. A pontuação maior a ser atingida pela criança era 160 pontos e a menor, zero.

A seguir, é exposta a coleta e análise dos dados obtidos com a aplicação dos instrumentos mediante a leitura das duas histórias narrativas.

\subsection{Coleta e análise dos dados}

A partir da aplicação dos instrumentos de pesquisa, apresentam-se os dados coletados expostos em tabelas que constituem cada item. Primeiramente, são expostos os dados referentes ao texto "A flor e o passarinho" (texto 1). Os dados coletados são apresentados conforme a ordem de aplicação dos instrumentos de pesquisa.

A tabela 1 mostra a classificação geral das respostas dos sujeitos do $3^{\circ}$ ano e os escores totais correspondentes na tarefa de compreensão da história.

Tabela 1 - Classificação das respostas e resultados obtidos na tarefa de compreensão leitora Texto $1 / 3^{\circ}$ ano

\begin{tabular}{cccccccccc}
\hline \multirow{2}{*}{ Sujeito } & Questão & Questão & Questão & Questão & Questão & Questão & Questão & Questão & Escore \\
& 1 & 2 & .3 & 4 & 5 & 6 & 7 & 8 & \\
\hline S1 & III & III & III & II & II & II & III & III & 130 \\
S2 & III & II & III & II & II & II & III & III & 120 \\
S3 & II & III & III & III & III & II & III & II & 130 \\
S4 & III & III & III & II & III & II & III & III & 140 \\
S5 & III & III & III & III & III & III & III & III & 160 \\
S6 & II & III & III & II & II & II & III & II & 110 \\
S7 & III & III & III & III & III & III & III & III & 160 \\
S8 & III & III & III & III & III & III & III & III & 160 \\
S9 & III & III & III & III & II & III & III & III & 150 \\
S10 & III & III & III & III & II & III & III & III & 150 \\
S11 & III & III & III & III & III & II & III & III & 150 \\
S12 & II & III & III & II & III & III & III & III & 140 \\
S13 & III & III & III & III & II & III & III & III & 150 \\
S14 & III & III & III & III & II & III & III & III & 150 \\
S15 & III & III & III & III & II & II & III & III & 140 \\
\hline
\end{tabular}


Entre os quinze sujeitos, alunos do $3^{\underline{a}}$ ano, apenas três atingiram a pontuação máxima - S5, S7 e S8 - cinco sujeitos alcançaram 150 pontos - S9, S10, S11, S13 e S14 - e três sujeitos - S4, S12 e S15, 140 pontos. Ao todo, onze sujeitos obtiveram um alto desempenho na tarefa de compreensão da história, mostrando assim que suas respostas estavam precisas em relação à história, sendo algumas de natureza inferencial. Os demais sujeitos registraram um médio grau de desempenho, variando de 130 a 110 pontos. Os sujeitos S1 e S3 conseguiram 130 pontos, o sujeito S2, 120 e o sujeito S6, 110 pontos, sendo este com o mais baixo escore.

Realizou-se também um levantamento dos tipos de respostas mais frequentes de acordo com as perguntas realizadas, abrangendo diferentes partes do texto. 0 quadro 1 mostra os resultados.

Quadro 1: Classificação das respostas por pergunta - Texto 1/3ํano

\begin{tabular}{|c|c|c|c|c|c|c|c|c|c|}
\hline & Questão & Questão & Questão & Questão & Questão & Questão & Questão & Questão & Total \\
Tipo 1 & 1 & 2 & 3 & 4 & 5 & 6 & - & - & - \\
\cline { 2 - 11 } & - & - & - & - & - & - & 7 & & 24 \\
\hline Tipo 2 & 3 & 1 & - & 4 & 7 & 7 & 15 & 13 & 96 \\
\hline Tipo 3 & 13 & 14 & 15 & 12 & 6 & 8 & 15 & 15 & 120 \\
\hline Total & 15 & 15 & 15 & 15 & 15 & 15 & 15 & - & \\
\hline
\end{tabular}

O tipo de resposta 3 predominou em grande parte das perguntas, especialmente nas perguntas $1,2,3,7$ e 8 . De um total de 120 respostas, 96 foram desse tipo. As respostas do tipo 2 ocorreram em quase todas as perguntas, com exceção das perguntas 3 e 7. Do total de 120 respostas, 24 foram desse tipo, predominando nas perguntas 4, 5 e 6, ou seja, as respostas dos sujeitos nessas três perguntas foram correspondentes àquilo que lhes foi perguntando, mas não de forma precisa. Não houve respostas do tipo 1 , constatando-se que todas as respostas dos sujeitos de alguma maneira estavam de acordo com a pergunta.

As respostas com maior incidência do tipo 2, pergunta 4, $O$ que passarinho fez para ajudar a flor, os alunos S1, S2, S6 e S12 apenas responderam que ele foi ao quintal e pegou as sementes. Na pergunta 5, Qual foi a surpresa que a flor teve quando acordou, sete sujeitos disseram que ela apenas tinha amigos. Na pergunta 6, Por que o quintal ficou parecendo um lindo jardim, sete sujeitos detiveram-se na ação do passarinho e responderam que o passarinho tinha plantado as sementes. 
A análise a seguir, mostra o desempenho dos alunos de $2^{\circ}$ ano na história "A flor e o passarinho". A tabela 2 apresenta o escore desses sujeitos na tarefa de compreensão leitora.

Tabela 2 - Classificação das respostas e resultados obtidos na tarefa de compreensão leitora Texto $1 / 2^{\circ}$ ano

\begin{tabular}{cccccccccc}
\hline \multirow{2}{*}{ Sujeitos } & Questão & Questão & Questão & Questão & Questão & Questão & Questão & Questão & Escore \\
& 1 & 2 & 3 & 4 & 5 & 6 & 7 & 8 & 120 \\
S1 & II & III & III & III & II & II & II & III & 130 \\
S2 & III & III & III & III & II & III & II & II & 160 \\
S3 & III & III & III & III & III & III & III & III & II \\
S4 & III & III & III & II & II & III & III & III & 140 \\
S5 & III & II & III & III & III & II & III & III & 140 \\
S6 & III & III & III & III & I & II & III & III & 130 \\
S7 & III & III & III & III & III & II & II & III & 140 \\
S8 & III & III & III & III & III & III & II & III & 150 \\
S9 & III & III & III & II & II & III & I & III & 120 \\
S10 & II & III & III & II & III & III & III & III & 140 \\
S11 & III & III & III & II & III & III & III & II & 140 \\
S12 & III & III & III & III & III & II & III & III & 150 \\
S13 & III & III & III & III & III & III & III & III & 160 \\
S14 & III & III & III & III & II & III & II & III & 140 \\
S15 & III & III & III & III & II & III & III & III & 150 \\
\hline
\end{tabular}

Entre os alunos do $2^{\circ}$ ano, apenas dois conseguiram a pontuação máxima de 160 pontos, os sujeitos S3 e S13. Mesmo assim, a grande maioria teve um alto desempenho, pois três sujeitos - S8, S12 e S15 - atingiram 150 pontos e seis sujeitos - S4, S5, S7, S10, S11 e S14 - obtiveram 140 pontos, totalizando 11 sujeitos. Os demais alcançaram entre 130 pontos - os sujeitos S2 e S9 - e 120 pontos - os sujeitos S1 e S9 - tendo um médio grau de desempenho.

Um levantamento dos tipos de respostas mais frequentes também foi realizado. 0 quadro 2 apresenta os resultados. 
Quadro 2: Classificação das respostas por pergunta- Texto 1/2ano

\begin{tabular}{|c|c|c|c|c|c|c|c|c|c|}
\hline & $\begin{array}{c}\text { Questão } \\
1\end{array}$ & $\begin{array}{c}\text { Questão } \\
2 \\
\end{array}$ & $\begin{array}{c}\text { Questão } \\
3 \\
\end{array}$ & $\begin{array}{c}\text { Questão } \\
4\end{array}$ & $\begin{array}{c}\text { Questão } \\
5\end{array}$ & $\begin{array}{c}\text { Questão } \\
6\end{array}$ & $\begin{array}{c}\text { Questão } \\
7\end{array}$ & $\begin{array}{c}\text { Questão } \\
8 \\
\end{array}$ & Total \\
\hline Tipo 1 & - & - & - & - & 1 & - & 2 & - & 3 \\
\hline Tipo 2 & 2 & 2 & 1 & 4 & 5 & 5 & 2 & 3 & 23 \\
\hline Tipo 3 & 13 & 13 & 14 & 11 & 10 & 10 & 11 & 12 & 94 \\
\hline Total & 15 & 15 & 15 & 15 & 15 & 15 & 15 & 15 & 120 \\
\hline
\end{tabular}

As respostas do tipo 3 predominaram em todas as perguntas, totalizando 94 de um total geral de 120 respostas, especialmente nas questões 1, 2, 3 e 8 . As respostas do tipo 2 ocorreram em todas as perguntas também, totalizando 23. Elas aconteceram com maior frequência nas perguntas 4, 5 e 6 . Quanto às respostas de tipo 1 , incidiram apenas sobre as questões 5 e 7, totalizando apenas 3.

Percebeu-se que a parte do texto referente à situação-problema foi compreendida com maior facilidade, conforme classificação das respostas obtidas pelos sujeitos nas perguntas referentes a essa parte da história, o que corrobora o estudo de Brandão e Spinillo (1998), que menciona que determinadas partes da história são consideradas mais difíceis para crianças como a resolução e a consequência. Segundo as autoras, parece haver uma gradação de dificuldades que varia em função das partes do texto colocadas em evidência através das perguntas.

A seguir, exibem-se os dados obtidos pelos alunos no segundo texto intitulado "A abelha". A tabela 3 expõe as respostas dadas pelos sujeitos do $3^{\circ}$ ano no texto 2 .

Tabela 3 - Classificação das respostas e resultados obtidos na tarefa de compreensão leitora Texto $2 / 3^{\circ}$ ano

\begin{tabular}{cccccccccc}
\hline \multirow{2}{*}{ Sujeitos } & Questão & Questão & Questão & Questão & Questão & Questão & Questão & Questão & \multirow{2}{*}{ Escore } \\
& 1 & 2 & 3 & 4 & 5 & 6 & 7 & 8 & \\
\hline S1 & II & III & III & III & II & III & II & III & 130 \\
S2 & III & II & III & II & III & III & II & III & 130 \\
S3 & II & II & III & III & II & III & III & III & 130 \\
S4 & II & III & III & III & II & III & III & III & 140 \\
S5 & II & III & III & III & III & III & III & III & 150 \\
S6 & III & III & III & III & I & III & III & I & 120 \\
S7 & III & III & III & II & III & III & III & III & 150 \\
\hline
\end{tabular}


Tabela 3 (continuação) - Classificação das respostas e resultados obtidos na tarefa de compreensão leitora - Texto $2 / 3^{\circ}$ ano

\begin{tabular}{cccccccccc}
\hline \multirow{2}{*}{ Sujeitos } & Questão & Questão & Questão & Questão & Questão & Questão & Questão & Questão & \multirow{2}{*}{ Escore } \\
& 1 & 2 & 3 & 4 & 5 & 6 & 7 & 8 & \\
\hline S8 & III & III & III & III & III & III & III & III & 160 \\
S9 & III & III & III & III & III & III & III & III & 160 \\
S10 & III & III & III & III & III & III & III & III & 160 \\
S11 & II & II & III & III & III & III & III & II & 130 \\
S12 & III & III & III & III & III & III & III & III & 160 \\
S13 & III & II & III & III & III & III & III & III & 150 \\
S14 & III & III & III & II & III & III & III & III & 150 \\
S15 & III & III & III & II & III & III & III & III & 150 \\
\hline
\end{tabular}

Quatro sujeitos do 3ª ano conseguiram a pontuação máxima - S8 e S9, S10 e S11 um número maior do que na mesma tarefa do texto 1 . Os sujeitos S5, S7, S13, S14 e S15 atingiram 150 pontos e o sujeito S4 obteve 140 pontos, totalizando nove sujeitos com um alto desempenho na tarefa de compreensão da história. Os demais sujeitos registraram um médio grau de desempenho, uma vez que alcançaram entre 130 e 120 pontos; sujeitos S1, S2, S3 e S11, 130 pontos e o sujeito S6, 120 pontos.

Realizou-se também um levantamento dos tipos de respostas mais frequentes. 0 quadro 3 expõe os resultados.

Quadro 3: Classificação das respostas por pergunta- Texto 2/3ano

\begin{tabular}{|c|c|c|c|c|c|c|c|c|c|}
\hline & $\begin{array}{c}\text { Questão } \\
1\end{array}$ & $\begin{array}{c}\text { Questão } \\
2\end{array}$ & $\begin{array}{c}\text { Questão } \\
3\end{array}$ & $\begin{array}{c}\text { Questão } \\
4\end{array}$ & $\begin{array}{c}\text { Questão } \\
5\end{array}$ & $\begin{array}{c}\text { Questão } \\
6\end{array}$ & $\begin{array}{c}\text { Questão } \\
7\end{array}$ & $\begin{array}{c}\text { Questão } \\
8\end{array}$ & Total \\
\hline Tipo 1 & - & - & - & - & 1 & - & & 1 & 2 \\
\hline Tipo 2 & 5 & 4 & - & 4 & 3 & - & 2 & 1 & 19 \\
\hline Tipo 3 & 10 & 11 & 15 & 11 & 11 & 15 & 13 & 13 & 99 \\
\hline Total & 15 & 15 & 15 & 15 & 15 & 15 & 15 & 15 & 120 \\
\hline
\end{tabular}

As respostas do tipo 3 predominaram em grande parte das perguntas, especialmente nas perguntas 1, 2, 3, 6, 7 e 8. De um total de 120 respostas, 99 foram desse tipo, sendo estas classificadas como precisas.

As respostas do tipo 2, ocorrem em quase todas as perguntas, com exceção das pergunta 3, Quem Zita encontrou quando voltava para a colmeia, e a pergunta 6, $O$ que Zita fez pra ajudar o passarinho, enfatizando-se que as crianças voltaram a sua atenção 
para a situação-problema da história e a resolução do mesmo. As respostas do tipo 2 ocorreram com maior incidência nas pergunta 1, $O$ que as abelhas faziam todas as manhã, na pergunta 2, Por que Zita era sempre a última a voltar, e na pergunta 4, Por que o passarinho não podia voar, sendo que o maior número de respostas desse tipo não passou de 4 para cada questão, estando todas de acordo com a história, mas não de forma específica.

Houve apenas duas respostas do tipo 1, ambas dadas pelo sujeito S6. Na questão 5, Por que Zita perguntou pra rainha se podia ajudar o passarinho, ele respondeu que não sabia, e sobre a pergunta 8, Por que as amigas de Zita ficaram muito orgulhosas da pequenina, ele disse que a abelhinha tinha contado uma história para as amigas. Referente a essa resposta, indaga-se se a criança tivesse sido novamente questionada sobre qual história a abelha Zita contou, se sua resposta teria sido de ordem pontual. Talvez ela não tenha expressado, pois julgou não necessário, pressupondo que seu interlocutor tivesse compreendido seu raciocínio inferencial, isso porque nas demais questões, o sujeito S6 apresentou um bom desempenho. A tabela 4 mostra a classificação das respostas dos sujeitos do 2o ano na história "A abelha".

Tabela 4 - Classificação das respostas e resultados obtidos na tarefa de compreensão leitora Texto $2 / 2^{\circ}$ ano

\begin{tabular}{cccccccccc}
\hline \multirow{2}{*}{ Sujeitos } & Questão & Questão & Questão & Questão & Questão & Questão & Questão & Questão & \multirow{2}{*}{ Escore } \\
& 1 & 2 & 3 & 4 & 5 & 6 & 7 & 8 & \\
\hline S1 & II & II & III & II & II & III & II & III & 110 \\
S2 & II & I & III & II & III & III & III & III & 120 \\
S3 & III & III & III & III & III & III & III & III & 160 \\
S4 & III & III & III & III & II & III & III & III & 150 \\
S5 & III & III & III & II & III & III & III & III & 150 \\
S6 & II & III & III & III & II & III & II & III & 130 \\
S7 & III & II & III & III & II & III & III & III & 140 \\
S8 & III & II & III & III & III & III & III & III & 150 \\
S9 & II & II & III & III & III & III & II & I & 110 \\
S10 & II & II & III & III & III & III & III & III & 140 \\
S11 & II & III & III & III & III & III & II & III & 140 \\
S12 & II & II & III & III & III & III & III & III & 140 \\
S13 & III & III & III & III & III & III & III & III & 160 \\
S14 & III & III & III & III & III & III & II & III & 150 \\
S15 & II & III & III & III & III & III & II & III & 140 \\
\hline
\end{tabular}


Apenas os sujeitos S3 e S13 chegaram à pontuação máxima da tarefa, 160 pontos. Quatro sujeitos atingiram 150 pontos, S4, S5, S8 e S14. Os sujeitos S7, S10, S11, S12 e S15 alcançaram 140, apresentando um alto nível de desempenho ao executar a tarefa. Os demais mostraram um desempenho mediano, variando entre 130 pontos, sujeito $S 6,120$ pontos, sujeito S2, e 110 pontos, S1 e S9.

Realizou-se também um levantamento dos tipos de respostas mais frequentes. 0 quadro 4 exibe os resultados.

Quadro 4: Classificação das respostas por pergunta - Texto $2 / 2^{\circ}$ ano

\begin{tabular}{|c|c|c|c|c|c|c|c|c|c|}
\hline & $\begin{array}{c}\text { Questão } \\
1\end{array}$ & $\begin{array}{c}\text { Questão } \\
\text { Tipo 1 }\end{array}$ & \begin{tabular}{c} 
Questão \\
\cline { 2 - 10 }
\end{tabular} & - & $\begin{array}{c}\text { Questão } \\
4\end{array}$ & $\begin{array}{c}\text { Questão } \\
5\end{array}$ & $\begin{array}{c}\text { Questão } \\
6\end{array}$ & $\begin{array}{c}\text { Questão } \\
7\end{array}$ & $\begin{array}{c}\text { Questão } \\
8\end{array}$ \\
\hline Tipo 2 & 8 & 6 & - & 2 & 4 & 15 & 6 & - & 26 \\
\hline Tipo 3 & 17 & 18 & 15 & 13 & 11 & 8 & 19 & 14 & 92 \\
\hline Total & 15 & 15 & 15 & 15 & 15 & 15 & 15 & 15 & 120 \\
\hline
\end{tabular}

Em relação à frequência das respostas, 92 foram do tipo 3, de um total de 120. Do tipo 2, 26, que ocorreu em quase todas as perguntas, com exceção das perguntas 3, 6 e 8, fato similar ao grupo do $3^{\text {o }}$ ano, excluindo-se a pergunta 8 , que teve uma incidência desse tipo naquele grupo.

0 tipo de resposta 2 incidiu em número significativo nas perguntas 1, com 8 respostas de um total de quinze sujeitos. Quando perguntado aos sujeitos, $O$ que Zita fazia todas as manhãs, muitos responderam que a abelhinha ia buscar flores. Acredita-se que esses sujeitos, para responderem à questão, basearam-se em seu conhecimento de mundo, relacionando abelhas a flores. A pergunta 7, Qual foi a surpresa que Zita teve em uma manhã, foi respondida por seis sujeitos de forma não precisa.

Houve apenas duas respostas do tipo 1, dadas por sujeitos diferentes em perguntas diferentes, a pergunta 2, Por que Zita era sempre a última a voltar, que o sujeito S2 disse não saber a resposta e a pergunta 8, Por que as amigas de Zita ficaram muito orgulhosas da pequenina, que o sujeito S9 respondeu que Zita não demorou para chegar à colmeia. Conforme já apresentado nesta pesquisa, tal resultado pode ser devido ao fato de os sujeitos deterem-se na situação-problema da história e na resolução da mesma. 
Conforme já mencionado, investigou-se também neste estudo o ambiente de letramento dos sujeitos de pesquisa. A tabela 5 mostra o número total de sujeitos em cada item averiguado.

Tabela 5 - Resultado do instrumento de caracterização do ambiente de letramento

\begin{tabular}{l|c|c|c|c}
\hline CARACTERIZAÇÃO DO AMBIENTE DE & $3^{\text {o ano }}$ & $2^{\text {o }}$ ano & $3^{\circ}$ & $2^{\text {o }}$ \\
LETRAMENTO & & & & \\
\hline Tem jornais, revistas e livros em casa? & 10 & 4 & $70 \%$ & $26 \%$ \\
Lê livros em casa? & 11 & 8 & $77 \%$ & $54 \%$ \\
Frequenta a biblioteca da escola? & 10 & 8 & $70 \%$ & $54 \%$ \\
Alguém lia pra você quando ainda não sabia ler? & 13 & 8 & $86 \%$ & $54 \%$ \\
\hline
\end{tabular}

Os dados revelam que $70 \%$ dos sujeitos participantes do $3^{\circ}$ ano possuem material para leitura em casa. $77 \%$ dos sujeitos relatam ler livros no ambiente familiar, sendo que $70 \%$ frequentam a biblioteca escolar. Dos 15 sujeitos participantes desse grupo, $80 \%$ frequentaram a pré-escola e $86 \%$ mencionam que algum membro da família lia para eles quando ainda não sabiam ler.

Quanto aos participantes do $2^{\circ}$ ano, 26\% mencionam ter jornais, livros e revistas em casa. $54 \%$ desses sujeitos leem livros e frequentam a biblioteca da escola. $70 \%$ frequentam a escola desde a pré-escola. Entre esses 15 sujeitos, 54\% destacam ter um membro da família que lhes fazia o papel de leitor quando ainda não sabiam ler.

Finalizada a exposição e análise dos dados coletados, no próximo capítulo, partese para as considerações finais do presente estudo.

\section{Considerações finais}

Este artigo procurou apresentar um recorte da dissertação de mestrado que investigou a relação entre a compreensão leitora e o grau de desenvolvimento da consciência textual (BARBOZA, 2014). Este estudo deteve-se em abordar o desempenho de crianças nas tarefas de compreensão leitora. Os sujeitos foram 30 alunos de $2^{\circ}$ e $3^{\circ}$ o anos do Ensino Fundamental, de uma escola pública municipal, da região metropolitana de Porto Alegre.

A situação de aplicação dos instrumentos ocorreu em dois momentos distintos, com um intervalo de uma semana. Na primeira entrevista, cabia aos alunos lerem uma 
história e responderem às oito questões de compreensão feitas pela pesquisadora. No segundo encontro, os alunos também liam outra história narrativa e realizavam a tarefa similar de perguntas de compreensão. Ainda, investigou-se a influência das variáveis ambiente de letramento no contexto familiar e escolaridade no desempenho dos alunos.

Verificou-se que os grupos apresentaram um bom nível de compreensão nas tarefas propostas. Através de uma classificação para as respostas dadas pelos alunos, notou-se que o desempenho deles variou de alto para médio. As respostas dos sujeitos para as questões formuladas foram bastante precisas, sendo poucas não específicas, até mesmo naquelas que eram inferenciais. Ainda, esse tipo de tarefa de classificação das respostas revelou-se ser mais rico do que aquelas que utilizam certo/errado, o que possibilitou analisar a precisão das respostas, assim como as dificuldades em relação às partes da história.

É relevante mencionar que o grupo do $3^{\circ}$ ano registrou escores mais elevados em comparação aos sujeitos do $2^{\underline{o}}$ ano na execução dessa tarefa, embora a média de desempenho geral entre os alunos não tenha oscilado muito. Isso aconteceu tanto em relação ao primeiro quanto ao segundo texto; as médias entre os alunos de $2^{\circ}$ e $3^{\circ}$ anos pouco variaram.

Em relação ao ambiente de letramento, percebeu-se que os melhores resultados foram obtidos pelos alunos que possuíam hábitos de leitura, que tinham livros, sendo, constantemente, estimulados por seus familiares a ler. A partir do levantamento realizado com todos os participantes da pesquisa, averiguou-se que as práticas de letramento no contexto familiar para os sujeitos do $3^{\mathrm{o}}$ ano foram mais evidentes.

Embora tenha sido verificado que os alunos do $3^{\mathrm{o}}$ ano atingiram um melhor desempenho na realização das tarefas propostas, verificou-se que os escores atingidos por esses sujeitos distinguiram-se de forma pouco elevada em relação aos outros sujeitos de pesquisa. Apesar de os alunos do $3^{\mathfrak{0}}$ ano frequentarem a escola por um período de tempo maior, ou seja, esses alunos possuem um ano de vida escolar a mais que os do grupo do $2^{\text {o }}$ e uma idade superior, os índices não foram expressivos.

Diante de tal fato, considerando-se também o ambiente propício de letramento que esse grupo possui, evidenciou-se que a progressão do desempenho que se esperava entre esses alunos foi pouco considerável. 
Os resultados obtidos nessa pesquisa podem contribuir na área educacional para o objetivo primordial da leitura, a compreensão leitora. Este estudo fornece subsídios para que os professores conheçam os processos envolvidos na compreensão e o seu desenvolvimento. Ainda, é importante destacar que muitos estudos que abordam a compreensão leitora voltam-se para sujeitos que já não estão em período de alfabetização, diferentemente deste trabalho. Desse modo, sugere-se que mais pesquisas com este tema e com crianças entre 7 e 8 anos sejam realizados, bem como estudos que remetam aos elementos linguísticos presentes nos textos, que colaboram para o seu entendimento, e que podem favorecer o processo de ensino-aprendizagem.

\section{Referências}

BARBOZA, L. S. A relação entre compreensão leitora e consciência textual: um estudo com alunos do $2^{\circ}$ e $3^{\circ}$ anos do Ensino Fundamental. Dissertação de Mestrado. Porto Alegre: PUCRS, 2014.

BRANDÃO, A. C. P.; SPINILLO, A. G. Aspectos gerais e específicos na compreensão de textos. Psicologia: Reflexão e Crítica, v. 11, n. 2, Porto Alegre, 1998.

Produção e compreensão de textos em uma perspectiva de desenvolvimento. Estudos de Psicologia, v. 6, n. 1, p. 51-62, 2001.

COLOMER, T; CAMPS, A. Ensinar a Ler - Ensinar a Compreender. São Paulo: Artmed, 2002.

CORREA, J. Habilidades Metalinguísticas ligadas à sintaxe e morfossintaxe. Em MOTA, M. Desenvolvimento metalinguístico: questões contemporâneas. São Paulo: Caso do Psicólogo, 2009.

DEHAENE, S. Os neurônios da leitura. Porto Alegre: Penso, 2012.

FONTES, M. J. O.; CARDOSO-MARTINS, C. Efeitos da leitura de histórias no desenvolvimento da linguagem de crianças de nível socioeconômico baixo. Psicologia: Reflexão e Crítica, v. 17, n. 1, p. 83-94, 2004.

KATO, M. O aprendizado da leitura. 6ª ed. São Paulo: Martins Fontes, 2007.

KLEIMAN, A. Texto e Leitor. Campinas: Fontes, 1989.

KLEIMAN, A.; MORAES, S. Leitura e Interdisciplinaridade: tecendo redes nos projetos da escola. Campinas, SP: Mercado das letras, 2002. 
LEFFA, V. Aspectos da leitura: uma perspectiva psicolinguística. Porto Alegre: Sagra, DC Luzzatto, 1996.

MARCUSCHI, L.A.. Compreensão textual como trabalho criativo, Unesp, p. 89-103, 2004. Disponível em: http://acervodigital.unesp.br/bitstream/123456789/40358/3/01 d17t07.pdf. Acesso em 28 de abril de 2013.

PEREIRA, V. W.; SCLIAR-CABRAL, L. Compreensão de textos e consciência textual Caminhos para o ensino nos anos iniciais. Florianópolis: Editora Insular, 2012.

SCLIAR-CABRAL, L. Guia prático de alfabetização, baseado em princípios do sistema alfabético do português do Brasil. São Paulo: Contexto, 2003.

SMITH, F. Compreendendo a leitura: uma análise psicolinguística da leitura e do aprender a ler. Porto Alegre: Artes Médicas, 2003.

WOLFF, C. L. Compreensão de história e consciência fonológica de crianças pré-escolares. Dissertação de Mestrado. Porto Alegre: PUCRS, 2008.

Recebido em março de 2014.

Aceito em abril de 2014.

\section{ANEXO 1}

\section{História: A flor e o passarinho}

Era uma vez uma flor que morava num quintal cheio de árvores grandes. A flor vivia muito triste, pois não havia ninguém com quem pudesse conversar. As árvores grandes não gostavam dela e nunca a convidavam para brincar.

Um dia, a flor viu um passarinho e resolveu conversar com ele. Ela foi logo dizendo que estava muito triste e sozinha.

- Por que você está tão triste? Perguntou o passarinho. - Aqui fico muito sozinha, disse a flor. Não tenho amigos. Você poderia ajudar? tristeza.

- Não se preocupe, respondeu o passarinho, tenho uma ideia para acabar com sua

E lá se foi ele voando rápido para um jardim vizinho. Neste jardim o passarinho apanhou com o bico, várias sementes de flores.

À noite, voltou para o quintal onde a florzinha morava e enquanto ela dormia, plantou as sementes na terra. Naquela noite, choveu muito. Ao amanhecer, a flor teve uma grande surpresa. 0 quintal parecia um lindo jardim!

Desde então, a flor viveu muito feliz, pois agora tinha muitas amigas para conversar. 
ANEXO 2

Protocolo de compreensão leitora

\begin{tabular}{|l|l|}
\hline \multicolumn{1}{|c|}{ Perguntas } & Classificação \\
\hline 1 Qual o problema da flor? & 123 \\
\hline 2 O que ela mais queria? & 123 \\
\hline 3 Quem resolveu o problema da flor? & 123 \\
\hline 4 O que foi que o passarinho fez para ajudar a flor? & 123 \\
\hline 5 Qual foi a surpresa que a flor teve quando acordou? & 123 \\
\hline 6 Por que o quintal ficou parecendo um lindo jardim? & 123 \\
\hline 7 O que fez as sementes crescerem tão rápido? & 123 \\
\hline 8 Por que a flor ficou feliz no final da história? & 123 \\
\hline
\end{tabular}

\section{ANEXO 3}

\section{HISTÓRIA: A abelha}

Era uma vez uma abelha que morava em uma colmeia com centenas de companheiras. Seu nome era Zita. Ela era uma abelha muito pequena, a menor da colmeia.

Todas as manhãs, a abelhinha e suas companheiras saíam com seu baldinho à procura de flores. Assim que retiravam o néctar, as abelhas voltavam rapidamente para a colmeia para poder fabricar o mel. Só que com Zita era diferente. A abelhinha era sempre a última a chegar.

Um dia, Zita avistou um filhote de passarinho caído no chão. A abelhinha resolveu ajudar o passarinho. Ela perguntou para a rainha se podia alimentar a ave com mel até que ela pudesse voar.

Todas as manhãs, lá ia Zita com seu baldinho cheio de mel alimentar o passarinho. Ele começou a melhorar com a ajuda da abelha. 0 passarinho começou a voar aos poucos. Até que Zita teve uma grande surpresa: ela viu o passarinho fazendo piruetas pelo ar.

A pequena abelha voltou para a colmeia e contou o que aconteceu para todas suas amigas que ficaram muito orgulhosas da pequenina. 
ANEXO 4

Protocolo de compreensão leitora

\begin{tabular}{|c|c|}
\hline Questões & Classificação \\
\hline 1) 0 que Zita fazia todas as manhãs? & 123 \\
\hline 2) Por que ela era sempre a última a voltar pra colmeia? & 123 \\
\hline 3) Quem Zita encontrou quando voltava para a colmeia? & 123 \\
\hline 4) Por que o passarinho não podia voar? & 123 \\
\hline $\begin{array}{l}\text { 5) Por que Zita perguntou para a abelha rainha se podia ajudar o } \\
\text { passarinho? }\end{array}$ & 123 \\
\hline 6) O que Zita fez para ajudar o passarinho? & 123 \\
\hline 7) Qual foi a surpresa que Zita teve em uma manhã? & 123 \\
\hline 8) Por que as amigas de Zita ficaram muito orgulhosas da pequenina? & 122 \\
\hline
\end{tabular}

